ORiON, Vol. 1, No. 1, pp. 43-48

\title{
A COMPARISON OF ECONOMIC DECISION MAKING \\ USING NET PRESENT VALUE ANALYSIS VERSUS PRESENT VALUE RATIO COMBINED WITH A MINIMUM HURDLE RATE
}

\author{
ROBERT E.D. WOOLSEY \\ School of Mech. Eng. \\ $U$. of the Witwatersrand. \\ Johannesburg, South Africa \\ and \\ CHARLES E. LIENERT \\ Dept. of Mineral Economics \\ Colorado School of Mines \\ Golden, Colorado USA 80401
}

\section{$\underline{\text { ABSTRACT }}$}

The authors will show that using present value ratio combined with a minimum hurdle rate for economic decision making can lead to erroneous economic conclusions. Two examples are presented.

\section{WHY THIS PAPER WAS WRITTEN}

A recent painful experience between a nameless consultant and an equally nameless mining house prompted this article. The consultant was hired to do an independent evaluation of some multi-million rand investments being considered by the firm. The firm had recently converted from the common tool of net present value (NPV) and discounted cash flow rate of return (DCFROR) to present value ratio (PVR) combined with a minimum hurdle rate that must be satisfied by the project. The fact that such a combination can lead to absolutely erroneous economic conclusions is well known in the academic literature of economic evaluation, (see for example [1]). The fact being well known seems, however, to have little relevance to either what is still being taught or what is being done by companies doing economic evaluation. The consultant discovered in 
his work that indeed the computer program used by this firm could, and did, produce results that fell within the category of wrong answers. As this program was routinely used in matters involving some millions of rand, the consultant included in his report that this situation should be corrected imnediately. The result was, as expected, the consultant was informed that they had "always done it that way" and was subsequently fired on the spot. The purpose of this paper is to provide some examples of PVR combined with minimum hurdle rates that give, demonstrably, erroneous conclusions. The application of this information will be left as an exercise for, and to the thoughtful discretion of, the reader.

In these examples it is assumed that the economic setting in which the examples are analyzed is such that the cash flows for each project will definitely occur in the magnitudes given, and that all projects are based on $100 \%$ owner's equity.

\section{EXAMPLE I}

We first define PVR from reference [2] (Stermole, 1982) as follows:

$$
\text { PVR }=\frac{\text { NPV Q } i^{\star}}{\text { PW Net Investment Costs } 6 j^{\star}}
$$

where $i^{\star}$ is the company's minimum (acceptable) after tax rate of return. The only costs included in the denominator are those costs not covered by current or prior revenues.

Following Stermole [2] we will use in the examples a condensed notation for the single payment present worth factor and the uniform series present worth factor. We use $P / F_{i, n}$ as the single payment present worth factor whose value is calculated from the formula $\frac{1}{(1+i)^{n}}$. In the notation $P / F_{i, n}$, the $p$ is the unknown present value (or worth) of a known future value $F$. The $i$ represents the period compound interest rate, and the $n$ represents the number of interest compounding periods. Similarly, we use 
$P / A_{i, n}$ as the uniform series present worth factor (assuming end-of-period payments) whose value is calculated from the formula

$$
\frac{(1+i)^{n}-1}{i(1+i)^{n}}
$$

Now suppose that a firm has specified that the minimum acceptable after tax rate of return is $i^{\star}=20 \%$, and that a project must have a minimum PVR of .3 in order to be considered acceptable. This second criterion is added in the hope of selecting only the more durable projects. Those projects which can (subjectively) survive hard economic times and compete successfully in the marketplace.

Suppose further that the firm is presently considering two mutally exclusive income producing projects $A$ and $B$. The distributions of after tax cash flows are shown on the time diagrams below.

PROJECT A:

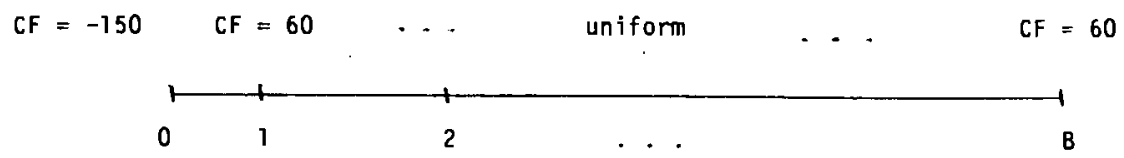

PROJECT B:

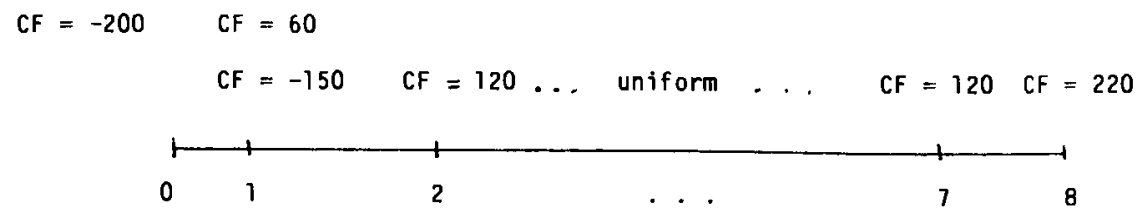

If we apply NPV analysis, then

$$
\begin{aligned}
N P V_{A}= & 60\left(P / A_{20,8}\right)-150=80.2, \text { and } \\
N P V_{B}= & 120\left(P / A_{20,6}\right)\left(P / F_{20,1}\right)+220\left(P / F_{20,8}\right) \\
& -90\left(P / F_{20,1}\right)-200=108.72
\end{aligned}
$$


We see from above that using the NPV criterion, Project B would be the economic choice. (A DCFROR analysis which would require both a total analys is of each project individually and an incremental analysis of project (B - A) would, of course, arrive at the same economic choice.)

Now if we apply the PVR technique combined with a minimum hurdle PVR value of .3, we get the following analysis:

Step 1: PVR applied to each project individually:

For project $A: \quad P_{A}=80.2 / 150=.53>0.3$.

For project B: $\quad P_{B}=10 B .72 /\left(200+(150-60)\left(P / F_{20,1}\right)\right)=.395>0.3$.

We note that both projects pass the economic evaluation criterion on an individual basis. Thus we must now examine the projects on an incremental basis.

Step 2: PVR applied to the incremental project $(B-A)$ :

$$
\text { For project }(B-A): \quad \operatorname{PVR}_{B-A}=\frac{28.52}{50+150\left(P / F_{20,1}\right)}=.163
$$

From the above we note that .163 is certainly less than 0.3 , which would lead to selection of $A$ as the economic choice. This is the opposite economic decision arrived at based on the NPV and DCFROR criteria. It is important to note that if the firm had set a hurdle PVR value of, say, 0.45, then we would have rejected project $B$ in step 1 above. This would obviously make step 2 unnecessary, leading to project $A$ to be selected as the economic choice.

\section{EXAMPLE II}

As a second example of how PVR combined with a minimum hurdle value can lead to economic decisions different from those given by NPV, consider the following situation. Suppose that we have two alternatives that provide a service such as well-logging. Suppose that the new and old alternatives have the following after tax cash flows as shown in the diagrams below: 
NEW ALTERNATIVE:

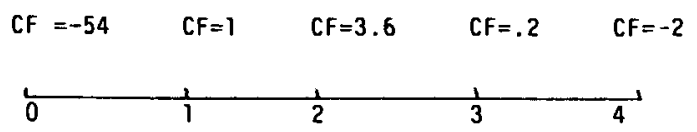

OLD ALTERNATIVE:

$\mathrm{CF}=0 \quad \mathrm{CF}=-20 \quad \mathrm{CF}=-21 \quad \mathrm{CF}=-22 \quad \mathrm{CF}=-23$

OLD

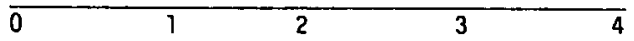

Applying a present worth cost analys is to these two alternatives, we have:

PWNEW $20 \%=\$ 51.5$,

and PWOLD $20 \%=\$ 55.1$

Using the present worth cost criterion, the economic choice is the NEW alternative. We may confirm this choice by the performance of an incremental NPV analys is as follows:

$$
\mathrm{CF}=-54 \quad \mathrm{CF}=21 \quad \mathrm{CF}=24.6 \quad \mathrm{CF}=22.2 \quad \mathrm{CF}=21
$$

(NEW-OLD)

$\begin{array}{llll}0 & 1 & 3 & 4\end{array}$

For this case, incremental NPV $20 \%=3.56$ which implies that the NEW alternative is preferable to the OLD. If we now apply the PVR criterion, we have:

$$
\operatorname{PVR}_{(N E W-O L D)}=3.56 / 54=.07 \text {. }
$$

Since the PVR (NEW-OLD) is .07 , which is certainly less than our requirement of 0.3 , this says that this particular economic criterion would select the OLD alternative, which again is the opposite economic choice arrived at based on both the NPV criterion and the present worth cost criterion. 


\section{SUMMARY}

The previous two examples have shown that if the PVR ratio is combined with a minimum hurdle rate that this decision making criterion can select the opposite economic alternative from that given by NPV and DCFROR. When correctly applied NPV, DCFROR, and PVR without a hurdle rate, will always yield the same economic results. Therefore, the authors suggest that any one of these three methods are completely appropriate to use, but that PVR combined with a minimum hurdle rate is unacceptable as an economic decision making tool.

\section{REFERENCES}

1. RICHARD H. BERNARD, a Comprehensive Comparison and Critique of Discounting Indices Proposed for Capital Investment Evaluation, The Engineering Economist, Vol. 16, No. 3, Spring 1971, pp. 157-186.

2. FRANKLIN J. STERMOLE, Economic Evaluation and Investment Decision Methods, Investment Evaluations Corporation, Golden, Colorado, (1983). 